\title{
Capacidade de escuta: questões para a formação docente em Educação Física
}

Vicente Molina Neto ${ }^{1}$ Rosane Kreusburg Molina ${ }^{2}$

No âmbito da educação física/ciências do esporte a utilização dos termos genéricos - esporte, formação, currículo, entre outros -, muito tem contribuído para a constituição do que hoje, talvez, seja um dos maiores problemas da área: a comunicação, portanto, a capacidade de escuta. Esses termos genéricos dificultam tanto a comunicação entre os segmentos profissionais que disputam pretensões de validez e verdade sobre o que é educação física, o que é esporte e como deve ser a formação de professores, quanto inviabilizam acordos mínimos sobre essa temática.

Por outro lado, os termos esporte, educação física e formação profissional são polissêmicos. Assim sendo, seus significados variam de sentido nos contextos onde eles acontecem, e em razão dos interesses, necessidades e das histórias de vida de seus protagonistas. E possível considerar, portanto, que grande parte das dificuldades para encontrar saídas consistentes no âmbito da formação em educação física deve-se à impossibilidade de haver concordância entre os diferentes segmentos envolvidos na questão: professores, administradores e estudantes. Assim, cabe o questionamento: de que tipo de Formação estamos falando? Formação Pessoal, Formação Inicial ou Permanente, AutoFormação, Formação em Serviço ou Pós-Graduação?

Também se observa um aumento de interesse em projetos de pesquisa cujo problema central é a Formação. No $X^{\circ}$ Congresso Brasileiro de Ciências do Esporte realizado em 1997, na cidade de Goiânia GO, quando o Colégio Brasileiro de Ciências do Esporte implementou os Grupos de Trabalhos Temáticos como forma de organizar seu evento científico, foram apresentados 40 trabalhos (24 apresen- tações orais e 16 posters) sobre Formação. Posteriormente, no $\mathrm{XI}^{\circ}$ Congresso Brasileiro de Ciências do Esporte, realizado em 1999, em Florianópolis SC, foram apresentados 83 trabalhos (21 apresentações orais e 62 posters), e na XII ${ }^{\mathrm{a}}$ edição do mesmo evento (2001) foram apresentadas 49 produções (33 apresentações orais e 16 posters) ${ }^{3}$, no Grupo Temático Formação, de um total 469 trabalhos aprovados nas diferentes temáticas. Já no VII ${ }^{\circ}$ Congresso de Educação Física e Epossível considerar Países de Língua parte das dificuldades
Portuguesa, realizado em 1999, na para encontrar saídas cidade de Florianópolis - consistentes no $\mathrm{SC}$, foram apresentados âmbito da formação 350 trabalhos, dos quais em educação física 35 estavam relacionados deve-se a com a temática da Formação. Na oitava edição impossibilidade de desse evento, realizado haver concordância em 2000, na cidade de entre os diferentes Lisboa - Portugal, foram segmentos envolvidos apresentados $\quad 729$ na questão: trabalhos (264 posters e professores, 465 comunicações orais), dos quais 73 estavam administradores $e$ relacionados com a estudantes. Formação. Recentemente, no Congresso Internacional de Motricidade Humana, realizado em novembro de 2001, na cidade de Muzambinho - Minas Gerais, entre mesas temáticas e posters foram apresentados 245 trabalhos de pesquisa, dos quais 14 focalizavam o tema Formação. 
A presente análise de dados permite dizer, sem pretensões de exatidão, que a produção científica dedicada à Formação, na área de conhecimento Educação Física, situa-se em uma banda móvel delimitada entre $5 \%$ e $10 \%$ de todo o volume da produção científica dessa área, o que significa um número ainda pequeno considerando-se a tradição e a produtividade dos pesquisadores da área.

Preocupado em discutir essa questão, o Colégio Brasileiro de Ciências do Esporte dedicou o último número de sua revista à essa temática. De outra parte, os números acima expostos provocam a seguinte interrogação: Há produção científica e conhecimento suficientes para se fazer as prescrições que se está fazendo sobre como deve ser a Formação no âmbito de nossa área de conhecimento?

A Formação de Professores de Educação Física é um tema ainda mais polêmico. Isso porque, além de agregar-se ao mesmo um debate político intermitente sobre os efeitos do processo de reconhecimento legal do Profissional de Educação Física (Lei n ${ }^{\circ} 9.696$, de $1^{\circ}$ de setembro de 1998), tanto na Formação Inicial dos professores, quanto na prática docente nos diferentes espaços institucionais onde a Educação Física acontece, também se observa nos discursos

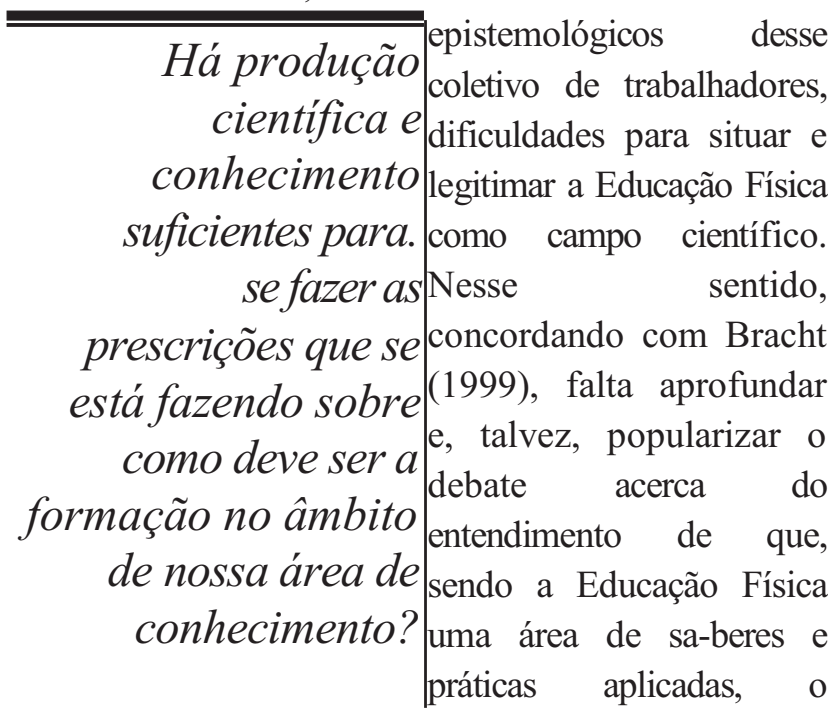
"objeto" ainda é de difícil demarcação, o que não acontece, por exemplo, na demarcação do "objeto" das Ciências ditas Bási- cas, ou seja, não se aplica à Educação Física uma delimitação do tipo disciplinar/monodisciplinar. Ao contrário, o sucesso da ação pedagógica depende do aporte de um conjunto de saberes e práticas oriundas de disciplinas científicas muito diferentes. Situação que tem contribuído para que a dúvida antes explicitada se acentue.

A preocupação com a Formação dos Professores e sua relação com a profissionalização docente não é um privilégio da Educação Física, nem se restringe ao contexto brasileiro. São processos relacionados, mas apresentam especificidade histórica e características constitutivas diferenciadas. Huberman e colaboradores (2000) assinalam, em retrospectiva histórica, que os estudos sociológicos paradigmáticos sobre a carreira de professor apontam para a necessidades de qualificar tecnicamente os professores para que possam enfrentar as dificuldades da prática em sala de aula.

Os interesses do Estado na Formação Docente também não é uma questão recente ${ }^{4}$, embora a reflexão sobre a Genealogia do Movimento pela Profissionalização Docente exista desde o inicio dos anos 80. Segundo Labaree (1999), é nos Estados Unidos que a questão ganha visibilidade internacional através da divulgação de dois informes elaborados por instituições americanas de apoio ao ensino: o Relatório do Carnegie Task Force on Teaching asa Profession elaborado por um grupo composto de representantes sindicais, funcionários públicos e administradores do ensino; o Documento Tomorrow's Teachers elaborado por um consórcio de escolas de magistério liderado por Henry W. Holmes, decano da Escola de Educação para Graduados da Universidade de Harvard. Os dois relatórios afirmam, à época, que a qualidade da educação só poderá melhorar se o ensino se transformar em uma "profissão de pleno direito".

Um dos debates internacionais mais significativos sobre a questão da profissionalização docente se desenvolve entre Gary Sikes, Katheleen Densmore e Nicolas Burbules, na Revista Educación y Sociedad, 
é a forma de qualificar o professorado, democratizar o ensino e garantir um trabalho de qualidade aos estudantes. Sikes considera que os professores não podem oferecer um trabalho de qualidade porque não são livres como intelectuais, pois têm pouca autonomia sobre seu trabalho, fato de fácil solução com a profissionalização. Em oposição, seus interlocutores sustentam que o profissionalismo se converteu em uma ideologia que falseia a realidade de trabalho dos Professores, pois mascara os conflitos reais do ensino e promovem a aceitação, pelo Professor, de circunstâncias adversas ao seu trabalho. Nessa perspectiva, o profissionalismo contribui para a reprodução das relações sociais injustas e desiguais, além de intensificar o trabalho docente.

Ao invés de considerar a escola um universo cultural dotado de dinâmicas próprias, que não depende só do trabalho do Professor, a defesa do profissionalismo vai considerar o Professor um indivíduo especializado autônomo, dotado de juízos idiossincráticos próprios sobre seus estudantes e sobre seu espaço de trabalho.

O nosso ponto de vista crítico, aqui, é que a ideologia do profissionalismo obstrui a possibilidade de um genuíno trabalho docente em equipe, dificulta o desenvolvimento de estratégias de ensino para enfrentar significativos problemas de aprendizagem e, obviamente, dificulta a criação de materiais didáticos adequados aos diferentes contextos em que o ensino acontece. O trabalho do Professor profissionalizado ficará restrito a um conhecimento específico no âmbito da aula (da disciplina), abrindo mão do macroplanejamento do ensino, da proposta curricular da escola e da interlocução qualificada com a comunidade educativa, ou seja, toda a complexidade e a riqueza de saberes e de práticas que circunscrevem, identificam e constituem a vida da escola seriam problemas de conhecimento para ocupação, deleite, pesquisa e teorização de outras disciplinas ou outros especialistas.

Entretanto, observando-se a prática docente nas escolas percebe-se que os discursos institucionais são permanentemente confirmados ou deformados, promovendo efeitos inesperados. Do mesmo modo, é inquietante observar a pretensão homogeneizadora veiculada em diferentes discursos e como as instituições responsáveis pela administração do ensino se manifestam refratárias à interlocução com a experiência docente. Os professores costumam agir por idiossincrasias próprias, construídas nos anos de docência, enquanto que as políticas públicas, na maioria dos casos, são elaboradas e se efetivam a partir do discurso acadêmico, sem ouvir os docentes com atenção. Esse fato revela a baixa capacidade de comunicação e de escuta entre ambos.

Investigando essa polarização, é possível identificar um problema que recebe pouca atenção da comunidade investigadora. Trata-se de uma (de)formação para a docência na escola pública. Ela emerge na formação inicial insuficiente para esse contexto e ganha proporções de ineficácia pelas políticas públicas que têm sido incapazes de propor atividades de Formação Permanente compatíveis e convergentes com a complexidade do ambiente escolar e áulico. Assim os professores são estimulados a sair da sala de aula, pela indústria da Formação Permanente, para serem atualizados em questões que pouco têm a ver com as dificuldades que encontram nas escolas (Molina Neto, 1997).

Do ponto de vista da crença, manifestada nos ideários políticos, a Formação dos professores faz parte das políticas sociais de governos de diferentes matizes e se estende por todas as instâncias do sistema educativo. A idéia dominante é adequar o currículo escolar às demandas sociais, por isso as administrações públicas e agências de formação elaboram planos e projetos de largo espectro, acreditando que investindo na formação de professores solucionarão os problemas educacionais e chegarão à almejada qualidade do ensino.

Além desse mito, que não se confirma com evidências seguras, outra crença que se estabelece, sem confirmação empírica, é a de que atualizando os professores com o dito "conhecimento de ponta" - últimas descobertas da ciência, resultados de pesquisas 
recém-divulgadas, etc. - sistematizado por especialistas, eles estarão mais aptos e motivados a ensinar melhor. A questão não é desconsiderar o trabalho dos especialistas, mas ponderar os limites de suas ações na interlocução pretendida com os contextos de atuação dos professores.

Outro mito que permeia a Formação dos professores, tanto a inicial quanto a permanente, é a maximização da tecnologia educacional. Essa ação também não gera os efeitos esperados porque são Como podemos ser oferecidas soluções técnicas reflexivos se não para enfrentar problemas escutamos o que o processuais relacionados à outro tem para nos Escola e à aula. Problemas dizer? Como agir que se situam no âmbito como professores trabalho docente, incluindo $_{\text {tractrão social do }}$ reãexivos se queremos a formação dos profesprescrever! 6 sores.

Um desafio a ser enfrentado na formação docente em Educação Física consiste em considerar que os professores apresentam interesses diferenciados em atividades de formação permanente de acordo com sua posição na carreira, seu contexto de trabalho, suas crenças e seu desenvolvimento socio-cultural (Huberman e colaboradores, 2000). Desafio que as Licenciaturas ainda não tomaram para si. Na maioria dos casos, a Formação Inicial está pautada por um discurso didático que se constitui sobre modelos idealizados de aluno, de professor e de escola sabidamente inadequados para enfrentar as situações reais de ensino/aprendizagem que se constituem em condições sociais complexas, portanto não-lineares.

Observamos que os estudantes deixam nossas escolas de formação entusiasmados, com conhecimento e críticos. Contudo, pouco reflexivos, pois thes falta a competência decisiva para esse tipo de atitude. Falta-lhes capacidade de escuta, cujo responsável é o modelo de formação historicamente construído na educação física brasileira. Como podemos ser reflexivos se não es- cutamos o que o outro tem para nos dizer? Como agir como professores reflexivos se queremos prescrever? ${ }^{6}$

Uma das alternativas para responder a essas perguntas seria incentivar a capacidade de escuta nas atividades de formação docente que pode gerar efeitos importantes no desenvolvimento da área de conhecimento e na qualificação dos professores de Educação Física. Possibilitará ao coletivo docente descortinar múltiplas percepções sobre os problemas educacionais, e construir modelos de ação educativa mais adequados aos tempos atuais, através de juízos autônomos e decisões didaticamente qualificadas sobre situações semelhantes em diferentes contextos sociais. Assim, os professores poderão sentir-se mais seguros para protagonizar propostas pedagógicas condizentes com a diversidade étnica, social, cultural e técnica que os estudantes evidenciam em nossas escolas, na atualidade.

Só é possível dialogar com o diferente, com a atenção vigilante gerada na capacidade de escutar os outros e a nós mesmos ou, como diz Perrenould (2001), quando tomamos consciência de nosso habitus ${ }^{7}$. Perceber a pertinência de trabalhar um determinado conhecimento com um segmento social ou grupo específico, ou ainda perceber que estudantes de um mesmo grupo necessitam de tempos e estímulos diferentes para a aprendizagem, são ações incompatíveis com a prescrição e a explicação, mas possíveis a partir da compreensão e da interlocução. E com capacidade de escuta que podemos perceber e respeitar a diversidade cultural, oferecendo ao diferente oportunidades de participar do diálogo intersubjetivo sem que o mesmo perca sua identidade. E óbvio que a capacidade de escuta não livrará o professor das dificuldades de gestão do seu "funcionamento". Estamos falando especificamente da gestão dos afetos e dos gostos pessoais e grupais presentes nas relações intersubjetivas. A capacidade de escuta facilitará essa gestão que, sabemos, influencia, inclusive, as estratégias didáticas dos professores.

\footnotetext{
"Ouvir as proposições de uma criança ou de um ado-
} 
lescente mobiliza determinados savoir-faire didáticos relacionados a intenção de instruir, mas também a preferências, preconceitos, simpatias ou antipatias, solidariedades ou exclusões. Não se conduz da mesma maneira um diálogo didático com uma criança amável ou com uma criança suja, obesa ou agressiva" (Perrenould, 2001:167).

Defendemos a formação docente vinculada à vida das escolas. Metas como autonomia docente, respeito à diversidade, dimensionamento adequado dos objetivos de ensino e desenvolvimento docente são possíveis quando encaramos o professor como participante de uma cultura docente. Um ser não-fragmentado que age relacionando sua formação com sua trajetória docente, com sua prática cotidiana, com o conhecimento construído na experiência, e com as crenças que elabora durante sua existência.

A capacidade de escuta que defendemos ao longo deste texto é uma atitude pessoal e docente. E muito mais do que ouvir. E, sobretudo, compreender os fenômenos na perspectiva e na lógica de seus protagonistas. Se constitui em uma metáfora que sintetiza um conjunto de procedimentos didáticos $\mathrm{e}$ metodológicos para efetivar programas, projetos e atividades de formação docente no âmbito da Educação Física, dentro de uma perspectiva devolucionista: devolver o protagonismo das decisões sobre o que ensinar e como ensinar às comunidades docentes e escolares.

Além da qualificação da capacidade de escuta, a formação dos professores de Educação Física precisa levar em conta outros desafios:

\section{a) Revisão da matriz disciplinar no currículo escolar}

O currículo escolar, tal como se configura a organização dos conteúdos e seu desenvolvimento, está constituído sob inspiração racionalista. Os conceitos estão cada um em seu lugar, organizados linearmente, em ordem crescente de complexidade dentro de um campo de saber. O tempo pedagógico e o movimento dos alunos são absolutamente controlados. Os grupos de estudantes são homogeneizados e as atividades uniformizadas, com alta prevalência das atividades intelectuais.

Sabemos que as crianças, os jovens e os adolescentes têm tempos próprios para diferentes aprendizagens e que a aprendizagem de conceitos, atitudes e procedimentos diferenciados demandam tempos diferentes. E de conhecimento comum que a Escola trata de temáticas que são transversais ao currículo, e que a aprendizagem de determinadas atitudes, procedimentos e conceitos é resultado da contribuição de várias disciplinas. Além disso, para atender a diversidade cultural, de gênero, procedência social e étnica, é preciso propor atividades didáticas conforme a biografia dos alunos. Se é preciso levar em consideração esse conjunto de variáveis na prática de ensino da Educação Física escolar é de se supor que a organização do currículo da Formação Inicial dos professores deve sofrer alterações significativas para que gere efeitos na prática desses professores.

Podemos dizer que o Parecer 009/2001 que estabelece Diretrizes Curriculares para a Formação de Professores da Educação Básica, em nível superior, Curso de Licenciatura de Graduação Plena, e o Parecer 021 / 2001 que dispõe sobre a duração e carga horária dos cursos de Formação de Professores, parecem ser tentativas razoáveis para aproximar a formação de professores da prática pedagógica escolar a fim de atender a diversidade socio-cultural dos estudantes. Porém, como sublinham Scheibe e Bazzo (2001), essas medidas ajustam as questões educacionais ao projeto de globalização neoliberal, porque nelas o ensino está desarticulado da análise e a pesquisa desarticulada da realidade. Dessa forma, é importante que a sociedade organizada mantenha atitude vigilante para que o Estado não perca a capacidade de intervenção em Projetos de Ensino corporativos e desprovidos de relevância social, cuja principal intenção é aligeirar a formação docente, mantendo as mesmas cotas de investimentos públicos a fim de satisfazer os insis- 
tentes apelos do mercado capitalista. Além disso, para essas autoras, a separação entre licenciatura e bacharelato pode resultar na ruptura do ensino com a pesquisa, sem contar que, considerando-se a perspectiva da Educação Social, a base da identidade de todo educador é a docência.

\section{b) Ação conjunta de diferentes disciplinas sobre orientação de complexos temáticos}

De acordo com Morin (1994), deve-se exercitar o pensamento complexo, organizando os saberes em campos e núcleos de saberes e de práticas, é uma medida necessária, assim como a ação conjunta de professores junto aos diversos grupos de estudantes. Também propor temas cotidianos interessantes, entre os quais as questões curriculares. Ao invés de um Professor em cada momento na sala de aula, articular ações dos professores do campo ou núcleo curricular. Assim, no ensino de um determinado conceito ou tratamento de um problema, por exemplo o uso responsável do corpo, autonomia do sujeito, violência, técnicas corporais e outros que afligem a sociedade atual, poderiam ser trabalhados pelo Professor de Educação Física, pelo Professor de Língua Portuguesa e pelo Professor de Artes, entre outros, porque o conhecimento é interdisciplinar.

\section{c) Refletir sobre a questão do tempo}

O tempo é um elemento que intervém nos habitus dos professores e na estruturação do trabalho docente, porque a programação do ensino considera aspectos quantitativos: o número de dias letivos, a carga horária diária para cada disciplina, entre outros. O currículo escolar $3 / 4$ a organização dos saberes privilegiados na Formação Inicial 3/4 também está organizado dessa forma, ou seja em uma dimensão temporal objetiva. Hargreaves (1994) denomina essa organização de monocrônica: a ação pedagógica se efetiva em um ato de cada vez, em uma progressão linear. Dessa forma, o tempo pedagógico e a aprendizagem são funções do tempo administrativo. A quantidade de tempo, componente essencialmente objetivo, define o conteúdo, amordaça a didática e racionaliza os recursos.

Se a sociedade e os trabalhadores do conhecimento trabalham com tempos policrônicos, subjetivos, em que se realizam várias coisas ao mesmo tempo, priorizando-se as relações e demonstrando-se alta sensibilidade aos contextos, é de se supor a existência de conflitos difíceis de superar no cotidiano docente. Pensar a Formação dos Professores de Educação Física numa sociedade movida pela informação, apesar de não abrir mão do conhecimento ${ }^{8}$, significa considerar e compreender o tempo e a cultura do estudante. Superar o anacronismo entre a formação monocrônica dos professores de Educação Física e a prática pedagógica necessária em uma sociedade pressionada pela velocidade da informação, sobretudo da informação digital, supõe a construção de novo habitus. Perrenould (2001), por exemplo, perspectiva esse novo habitus através de novos esquemas de percepção, de avaliação, de pensamento e de ação.

Em Porto Alegre, a Secretaria Municipal de Educação vem implementado um amplo processo de reestruturação curricular nas escolas municipais. Esse movimento reorganizou o projeto educacional do município, alterando os tempos e os espaços pedagógicos, rompendo com a antiga aula formal de educação física de 50 minutos. Nesse novo cenário, alguns professores vêm desenvolvendo experiências bastante significativas. Trabalhando em contextos em que o tempo e o espaço das aulas de Educação Física são flexíveis, e organizados em função das necessidades de aprendizagens significativas dos estudantes, realizam inovações curriculares nas formas de eleger e organizar os conhecimentos e nas estratégias didáticas. A integração da Educação Física na Área de Comunicação e Expressão do currículo escolar exige que o professor dialogue com seus colegas de outras disciplinas e tenha conhecimento suficiente para atuar em conjunto com eles em todas as etapas e momentos do processo de ensino-aprendizagem. Tais experiências os estimulam a questionar a lógica formal do ensino por disciplinas e os leva a pergun- 
tar: será possível inverter a lógica tradicional do ensino da Educação Física nas escolas, e o tempo pedagógico pautar o tempo administrativo? Quais os efeitos desse tipo de organização escolar na prática pedagógica dos professores de Educação Física? O quê e como ensinar nas aulas de Educação Física? As atuais ofertas de formação poderão suprir as necessidades desses professores? Quais ensinamentos dessa experiência docente podem ser incorporados aos currículos de Formação Inicial?

São questões difíceis de serem respondidas. Apropria formação docente, Inicial e Permanente, do Professor de Educação Física está fortemente pautada no modelo de formação centrado na transferência de conhecimento (Freire, 1997), isto é, prepara o Licenciado em Educação Física para ser um consumidor de conhecimentos, ou seja, torna-o habilitado para aplicar o saber produzido pelas agências de formação e de produção de conhecimento. A existência de algumas experiências didáticas inovadoras que se contrapõem a esse modelo de formação ainda não nos libertaram do colonialismo acadêmico que valoriza pouco o conhecimento que circula e é produzido pelos professores na sua prática docente diária.

Perrenould (2001) aponta para duas estratégias imprescindíveis para que se dê um salto qualitativo em favor de uma real inovação tanto na prática quanto na formação docente: transformar a estrutura e as condições da prática docente e favorecer a tomada de consciência dos professores, trazendo suas ações intuitivas para o controle da razão.

\section{d) Necessidade de incorporar o saber construído na prática docente ao currículo universitário}

Verificamos, com freqüência, que os professores de Educação Física escolar constróem saberes e práticas de grande valor e, geralmente, pouco conhecidas nos círculos universitários. Constatamos, em pesquisas já concluídas (Molina Neto, 1996 e Molina, 1997), através de fragmentos de histórias de vida, que os professores que elaboraram um conhecimento têm interesse em sistematizar suas experiências, ao mesmo tempo em que não encontram oportunidades para tal empreendimento. A ação dos professores de Educação Física nas escolas é, em grande parte, produto das condições materiais objetivas que enfrentam na escola, de seus interesses pessoais e do que aprendem nas instâncias de Formação. Daí, a necessidade de se estudar em profundidade os processo de formação desses professores que trabalham em novos modelos de organização escolar, permitindo-lhes incorporar ao currículo da formação inicial o conhecimento que produzem na ação docente.

A capacidade de escuta no Escutar, na ação âmbito da Formaçãopedagógica, significa Permanente se traduz em dar vez e voz a considerar no planejamento das quem normalmente atividades, as diferentes não tem.

etapas da carreira de um professor e os interesses predominantes em cada uma dessas fases: na graduação, oferecer situações de ensino que estimulem os estudantes à compreensão ao invés da prescrição. E importante enfatizar ao estudante de Educação Física que seu futuro aluno não é um cliente, mas um interlocutor. Além disso, é necessário que o currículo possibilite que o estudante desenvolva o ensino em situações concretas desde o inicio da Licenciatura. Seguindo Faingold (2001), pensamos em professores capazes de construir, com seus interlocutores, mecanismos de reflexão, de ajudálos a verbalizar suas ações, ou seja, entender os professores também como técnicos da. escuta.

No âmbito da pesquisa e da pós-graduação, a capacidade de escuta se traduz em procedimentos metodológicos centrados nas histórias de vida, etnografias educativas e estudos de caso.

Escutar, na ação pedagógica, significa dar vez e voz a quem normalmente não tem. Didaticamente, invés da proposição e da explicação, deve-se buscar a com- 
preensão. No âmbito das relações interpessoais, essa capacidade se traduz em diálogo com outros coletivos docentes; no âmbito da produção de conhecimento, a capacidade de escuta se traduz na pesquisa participante, socio-cultural, metodologias que integrem a pesquisa com o conhecimento de sala de aula. Observação mutua, escrita sistemática e atenta, entrevista de explicitação e história de vida são alguns mecanismos que, segundo Perrenolud (2001), podem favorecer a tomada de consciência e a transformação do habitus do professor.

Estamos convictos de que através do exercício da capacidade de escuta um outro tipo de conhecimento passará a integrar o conjunto de saberes e de práticas dos professores de Educação Física. O conhecimento subjetivo que emerge do significado que os diferentes atores dão a sua ação quando se comunicam nas aulas de Educação Física precisam ser explicitados e, sobretudo, escutados. Cremos profundamente nessa possibilidade como forma de encarar as demandas sociais do nosso tempo histórico. Apesar do decreto, cremos no compromisso com a lucidez. Contudo, parafrazeando Morin (2000), é fundamental termos a compreensão de que nossa lucidez depende da complexidade do modo de organização das nossas idéias.

\section{Referencias bibliográficas}

BRACHT, Valter. Educação Física \& Ciência: cenas de um casamento (in)feliz. Unijuí: Editora Unijuí, 1999.

BURBULES, Nicholas y DENSMORE, Katheleen. La persistência dei profesionalismo: Es duro abrirse camino. In: Educación y Sociedad, n. 111, p. 97-104. Madrid: Fuhem, 1992.

. Los limites de la profesionalización de la docência. In: Educación y Sociedad, n. 111, p. 67-83. Madrid: Fuhem, 1992.

FAINGOLD, Nadine. De estagiário a especialista: construir as competências profissionais. In: PERRENOULD, Philippe; PAQUAY, Leopold e ALTET, Évelyne C. Formando Professores Profissionais: Quais estratégias? Quais competências. Porto Alegre: Artmed, 2001.

FREIRE, Paulo. Pedagogia da Autonomia: Saberes necessários à prática educativa. Rio de Janeiro: Paz e Terra, 1997.

GIMENO SACRISTÁN, J. \& PÉREZ GÓMEZ, A. I. Comprendery transformar la enseñanza. 3. ed., Madrid: Morata, 1994.

HARGREAVES, Andy. Changing teachers, Changing times. Teachers' work and cultures in the postmodern age. Toronto: The Ontario Institute for Studies in Education, 1994.

HUBERMAN, Michael, THOMPSON, Charles L. e WEILAND, Steven. Perspectivas de la carrera del professor. In: Biddle, Bruce J., Good, Thomas L., Goodson, Ivor. La ensefianza y los profesores I. Barcelona: Paidós, 2000.

LABAREE, David F. Poder, conocimiento y racionalización de la ensefianza: Genealogía dei movimiento por la profesionalidad docente. In: Pérez Gómez, A. I.; Barquín Ruiz, J. y Angulo Rasco, J. F. (Org.) Desarrollo Profesional del Docente. Política, Investigación y Práctica. Madrid: Akal,1999.

MOLINA, Rosane K. Las Políticas Sociales y la Educación Social. El impacto de las políticas sociales en las comunidades urbanas de Ia ciudad de Porto Alegre. Estúdio de un caso. Tesis Doctoral. Barcelona: Departamento 
de Teoria e Historia de la Educación, Universidad de Barcelona, 1997.

MOLINA NETO, Vicente. A formação profissional em educação física e esportes. Anais do XI Congresso Brasileiro de Ciências do Esporte. Goiânia - GO: CBCE, 1997.

MOLINA NETO, Vicente. La cultura docente del profesorado de educación física de Ias escuelas públicas de Porto Alegre. Tese de Doutorado. Departamento de Didáctica y Organización Escolar. Universidad de Barcelona, España, 1996.

MORIN, Edgar. El método III: El conocimiento dei conocimiento. Madrid: Cátedra, 1994.

MORIN, Edgar. La mente bién ordenada. Barcelona: Editorial Seix Barral, 2000.

PERRENOULD Philippe. O trabalho sobre habitus na formação de professores: análise das práticas e tomada de consciência. In: PERRENOULD, Philippe; PAQUAY, Leopold e ALTET, Evelyne C. Formando Professores Profissionais: Quais estratégias? Quais competências. Porto Alegre: Artmed, 2001.

SCHEIBE, Leda e BAZZO, Vera L. Políticas Governamentais para a formação de professores na atualidade. In: Revista Brasileira de Ciências do Esporte, v. 22, n. 3, p. 9-21, maio 2001. Campinas: Editores Associados.

SCHÕN Donald A. La Formación de Profesionales Reflexivos: Hacia un nuevo diseño de la enseñanza y el aprendizaje en las profesiones. Barcelona: Paidós, 1992.

SCHÕN Donald A. El Profesional Reflexivo: Como piensan los profesionales cuando actúan. Barcelona: Paidós, 1998

SYKES, Gary. En defensa dei profesionalismo docente como una opción de política educativa. Educación y Sociedad, n. 11, p. 85-96. Madrid: Fuhem, 1992.

\section{Documentos Consultados}

X Congresso Brasileiro de Ciências do Esporte. Anais. Goiânia: CBCE, 1997.

XI Congresso Brasileiro de Ciências do Esporte. Anais. Florianópolis: CBCE, 1999.

XII Congresso Brasileiro de Ciências do Esporte. Anais. Campinas: CBCE, 2001.

VII Congresso de Educação Física e Ciências do Desporto dos Países de Língua Portuguesa. Anais. Florianópolis: UFSC - UDESC, 1999

VIII Congresso de Educação Física e Ciências do Desporto dos Países de Língua Portuguesa. Anais. Lisboa: UTL/FMH, 2000.

\section{Notas}

${ }^{1}$ Professor de Graduação e Pós-Graduação da ESEF/UFRGS.

2 Professora de Graduação da UNISINOS.

${ }^{3}$ Nessa edição do evento houve alteração na sistemática de inscrição. Diferentemente de edições anteriores, os trabalhos foram inscritos e julgados como apresentação oral ou pôster. Não foi permitido que os trabalhos que fo ram rejeitados para apresentação oral fossem incluídos nas sessões de posters. O objetivo desses números não é fazer algum tipo de comparação, mas dar uma idéia da produção científica da área no Brasil.

${ }^{4}$ Ver: Decreto Lei n. 1.212 de 17 de Abril de 1939, criando na Universidade do Brasil a Escola Nacional de Educação Física; Marinho de Oliveira, Vitor. Formação Profissional: Primeiras Influências. Revista Brasileira de Ciências do Esporte, n.19, v.2, Janeiro/98.

5 Gimeno Sacristán, J. \& Pérez Gómez A. I. (1994) analisam os modelos de formação utilizados para formar professores em diferentes contextos e os agrupam em quatro perspectivas: a) Perspectiva Acadêmica; b) Perspectiva Técnica; c) Perspectiva Prática; d) Perspectiva da Reflexão na Prática para a Reconstrução Social. Enquanto que nas 
Perspectivas Acadêmica e Técnica a ação do professor está centrada num saber de especialista, de caráter disciplinar e na racionalidade técnica, na Perspectiva da Reconstrução Social o professor centra sua ação na reflexão e na investigação em sala de aula. Sua ação é facilitar o desenvolvimento autônomo e emancipador de quem participa do processo educativo. A seleção do conteúdo está orientada pelo viés cultural e pela relevância social, objetivando estimular a capacidade de reflexão do estudante. Nessa perspectiva, o professor busca compreender sua ação pedagógica e seus efeitos, a fim de propor novas estratégias de ação para transformar sua prática e as condições sociais que a limitam.

${ }^{6}$ Para entender a noção de professor como profissional reflexivo, ler: Donald A. Schön. La Formación de Profesionales Reflexivos: Hacia un nuevo diseño de la enseñanza y ei aprendizaje en las profesiones. Barcelona: Paidós, 1992; Donald A. Schõn. El Profesional Reflexivo: Como piensan los profesionales cuando actúan. Barcelona: Paidós, 1998

${ }^{7}$ Habitus é uma noção trabalhada no âmbito da sociologia por Pierre Bourdieu, que Phillippe Perrenould utiliza para entender o conhe cimento em ação ou a epistemologia da ação que os professores constróem na prática docente. O habitus se constitui no conjunto de nossos esquemas de percepção, de avaliação, de pensamento e de ação. E ele que nos dá a capacidade de operar sem saber, em uma rotina econômica ou para fazer frente ao inusitado do cotidiano de nossas aulas.

${ }^{8}$ Morin (2000) comenta que para viver precisamos não só de uns conhecimentos, mas a transformação do conhecimento adquirido em saberes e a incorporação destes em todas as situações da vida. Para os processos educativos, diz o autor, trata-se de perseguir o objetivo de transformar as informações em conhecimento, de transformar o conhecimento em saberes, sempre orientando-se por finalidades definidas no Projeto Político Pedagógico em pauta.
Recebido em:21.02.2002

Aceito em: 05.03.2002 